\title{
Comparing Labetalol and Nitroglycerine on Inducing Controlled Hypotension and Intraoperative Blood Loss in Rhinoplasty: A Single-Blinded Clinical Trial
}

\author{
Mohamadreza Ghodraty, ${ }_{1}$ Ali Khatibi, ${ }^{1,}{ }^{*}$ Faranak Rokhtabnak, ${ }^{1}$ Mojtaba Maleki, ${ }^{2}$ and Fatemeh Parsa ${ }^{1}$ \\ ${ }^{1}$ Anesthesia Department, Firouzgar Hospital, Iran University of Medical Sciences, Tehran, Iran \\ ${ }^{2}$ Otolaryngology Department, Firouzgar Hospital, Iran University of Medical Sciences, Tehran, Iran \\ "Corresponding author: Ali Khatibi, Anesthesia Department, Firouzgar Hospital, Iran University of Medical Sciences, Tehran, Iran. Tel: +98-2182141360, E-mail: \\ alikhatibi2002@yahoo.com
}

Received 2016 October 08; Revised 2017 May 18; Accepted 2017 August 29.

\begin{abstract}
Background: Uncontrolled bleeding during surgery is one of the main predisposing factors for failure of the surgeon and complications following rhinoplasty. The current study aimed at comparing the effects of nitroglycerine and labetalol on the induction of controlled hypotension and bleeding volume during septorhinoplasty.

Methods: The current randomized, controlled, clinical trial enrolled 60 patients candidate for septorhinoplasty at Firoozgar hospital in Tehran, Iran, in 2 equal groups receiving either 0.1 to $1 \mathrm{mcg} / \mathrm{kg} / \mathrm{minute}$ nitroglycerine or 2 to $4 \mathrm{mg} / \mathrm{minute}$ labetalol to achieve a mean arterial blood pressure of about 60 to $65 \mathrm{mmHg}$. In case the targeted blood pressure was not achieved, isoflurane was added. Degree of bleeding was evaluated by the volume of suctioned blood and the blood remaining in surgical gauzes. Additionally, the surgeon's satisfaction with the surgical field was evaluated by a scoring system. The collected data were, then, compared between the study groups by the statistical methods.

Results: Based on the current study findings, systolic $(\mathrm{P}<0.001)$, diastolic $(\mathrm{P}=0.002)$, and the mean arterial blood pressures $(\mathrm{P}<$ $0.001)$ were significantly lower in the nitroglycerine group. Ninety percent of the patients in the labetalol group received isoflurane to achieve the targeted blood pressure defined as controlled hypotension. There was no significant difference between the groups regarding the volume of bleeding $(\mathrm{P}=0.75)$; however, the surgeons were more satisfied with nitroglycerine than labetalol $(\mathrm{P}<0.001)$. Conclusions: It was concluded that nitroglycerine had a better effect, in comparison to labetalol, on inducing the controlled hypotension in septorhinoplasty.
\end{abstract}

Keywords: Bleeding, Controlled Hypotension, Labetalol, Nitroglycerine, Rhinoplasty

\section{Background}

Septorhinoplasty is one of the most prevalent cosmetic surgeries in the world. The operation is accompanied by a trivial bleeding, but the presence of tiny vessels and variations in the anatomical structures and the close vicinity of these elements to brain and orbits can obscure the surgical field and complicate the operation. Therefore, controlling this bleeding is a great consideration during anesthetic management of the surgery (1-3).

One of the successful approaches to reduce bleeding tendency is to apply the controlled hypotension with a mean arterial blood pressure of 60 to $65 \mathrm{mmHg}$ that is quite safe in healthy patients. To achieve this purpose, peripheral vasodilators, beta-blockers, and a combination of anesthetic drugs (volatiles or intravenous (IV) are used (4).

An ideal hypotensive agent should has the following properties: easy to administer, short onset time, quick disappearance of its effect by the time the administra- tion is discontinued, rapid elimination without any toxic metabolite residues, and finally, predictable effects, dosedependent, and negligible while acting on vital organs (5).

Labetalol is an antihypertensive drug that antagonizes both alpha- and beta-receptors, simultaneously decreases heart rate, and makes vasodilation. This drug affects betareceptors 5 to 10 times more specifically than other receptors (6-8).This property hinders reflex tachycardia that usually emerges after inducing controlled hypotension by other antihypertensive vasodilator drugs. The effects of labetalol appear in 5 minutes; therefore, if the target blood pressure is not achieved, the next dose could be given in a short time. The half-life of this drug is about 4 to 5 hours and the maximal allowable dose in adults is $300 \mathrm{mg}$ in 24 hours (9-11).

Trinitroglycerin (TNG) can also produce hypotension by direct vasodilation especially in veins. But, as an adverse effect, this drug causes reflex tachycardia after inducing hypotension (12). On the other hand, due to its potential 
venodilating effect, some clinicians believe that this drug is not an optimal choice in head and neck surgeries where a vessel rich field is present and they claim that by this way TNG may even worsen the bleeding.

Therefore, the current study aimed at comparing TNG with labetalol in inducing controlled hypotension in septorhinoplasty and evaluating their potential benefits or side effects in this regard.

\section{Methods}

The current single-blind, randomized, controlled, clinical trial was conducted in an educational center (Firouzgar general hospital) in Tehran, Iran. Informed consent was obtained from all participants.

\subsection{Inclusion Criteria}

All the patients aged 18 to 65 years with ASA (American society of anesthesiology) physical status class I, scheduled for septorhinoplasty.

The current study was registered at www.IRCT.ir database under the code: IRCT201601129768N4.

Exclusion criteria were a history of nasal surgery, any allergic reactions to nitrates, and taking sildenafil or other similar drugs.

Patients were assigned into 2 groups by the simple randomization method (flipping a coin).

Both the patients and the surgeons were blind to grouping, but the anesthesiologist was aware of each patient group to be able to control any probable drug complications.

Sample size in each group was 30 patients; based on the previous studies conducted on controlled hypotension issue.

All of the patients received isotonic crystalloid (5 $\mathrm{mL} / \mathrm{kg}$ ) to replace compensatory intravascular expansion volume before starting anesthesia. Premedication and induction of anesthesia was similar in all patients: midazolam $0.03 \mathrm{mg} / \mathrm{kg}$ and fentanyl $3 \mathrm{mcg} / \mathrm{kg}$ for premedication, followed by propofol $2 \mathrm{mg} / \mathrm{kg}$ and atracurium $0.5 \mathrm{mg} / \mathrm{kg}$ to induce anesthesia. Mo maintain the anesthesia, propofol $100 \mathrm{mcg} / \mathrm{kg} /$ minute, atracurium $7 \mathrm{mcg} / \mathrm{kg} /$ minute, and fentanyl 50 mcg every 60 minutes were used. Head up position to 20 degrees was applied to all patients and all of the operations were performed by the same surgeon. After induction of anesthesia, patients were intubated and if they were hemodynamically stable, the surgeon allowed infiltrating local epinephrine to reduce bleeding tendency. Before starting surgical manipulation, if the mean arterial blood pressure was above $65 \mathrm{mmHg}$, infusion of TNG or labetalol according to the designed protocol was started to reach the target blood pressure (mean arterial blood pressure of 60 to $65 \mathrm{mmHg}$ ). The protocol was as follows:

In TNG group, the infusion started with 0.1 $\mathrm{mcg} / \mathrm{kg} /$ minute and increased to the upper limit of 1 $\mathrm{mcg} / \mathrm{kg} /$ minute if necessary. If during TNG infusion heart rate exceeded 100 beat/minute dosing was reduced to ameliorate this complication. The TNG used in the current study was a provided from Caspian Pharmaceutical Company in Iran, which contained $10 \mathrm{mg}$ of the drug in $2 \mathrm{~mL}$ containing vials.

In the labetalol group, if heart rate exceeded 60 beat/minute patients first received a bolus dose of 0.25 $\mathrm{mg} / \mathrm{kg}$, and then, infusion of labetalol started with 2 $\mathrm{mg} /$ minute, which increased to $4 \mathrm{mg} /$ minute if necessary. The current study limit in total amount of labetalol dosage was $300 \mathrm{mg}$. Any time during labetalol infusion, if heart rate dropped below 50 beat/minute, the infusion was held transiently and if heart rate dropped below 45 beat/minute, in spite of holding labetalol drip, then, 0.5 mg IV atropine was given. The used labetalol was a product of Kern Pharma SL Company in Spain containing 100 $\mathrm{mg}$ of the agent in $5 \mathrm{~mL}$ vials.

In each of the groups, if target blood pressure (controlled hypotension) was not achieved in any patient by the applied method, 0.5 MAC isoflurane was added to anesthetic drug regimens. Patients were monitored with noninvasive blood pressure (every 5 minutes), electrocardiography (ECG), and pulse-oximetry. Data were recorded every 15 minutes by an anesthetist who was ignorant of the type of administered hypotensive drug. On the other hand, the surgeon did not know anything about the drugs being used.

To minimize any complications related to tissue hypoperfusion, the duration of controlled hypotension was considered less than 2 hours. Bleeding volume was measured by the amount of suctioned blood and the blood remaining in surgical gauzes at the end of surgery (surgical gauzes were assumed to contain $10 \mathrm{~mL}$ of blood). The quality of surgical field was assessed by surgeon's satisfaction, based on a 5-option Likert scale rating system (very bad, bad, fair, good, very good).

\subsection{Statistical Analysis}

Sample size in each group was 30 patients; based on previous studies conducted on controlled hypotension issue; in the current study $\alpha$-value was $5 \%$ and $\beta$-value $80 \%$.

All the recorded data were analyzed with SPSS software version 20. Comparison between the quantitative data was accomplished by the student $t$ test and for the qualitative data chi-square test was used. P values less than 0.05 were considered significant. 


\section{Results}

Totally, 60 patients were incorporated into the study with mean age of $31.2 \pm 5.1$ years in the labetalol group and $30.9 \pm 5.1$ years in the TNG group. As shown in Table 1 , there was no significant difference between the 2 groups in terms of demographic characteristics.

In the labetalol group, 27 patients (90\%) received isoflurane to reach the target blood pressure, whereas no patient in the TNG group needed isoflurane for this purpose.

The average amount of bleeding was $134 \mathrm{~mL}$ in the labetalol group and $139 \mathrm{~mL}$ in the TNG group, which showed no significant difference $(\mathrm{P}=0.75)$.

Heart rate and blood pressure changes were analyzed and compared between the groups by repeated measure test. The current study found that in TNG group, heart rate was significantly higher than that of labetalol group during surgery (Figure 1). Moreover, in the labetalol group, 5 patients had bradycardia at the time of giving the first bolus dose and 2 patients needed atropine because of heart rates $<40$ beat/minute.

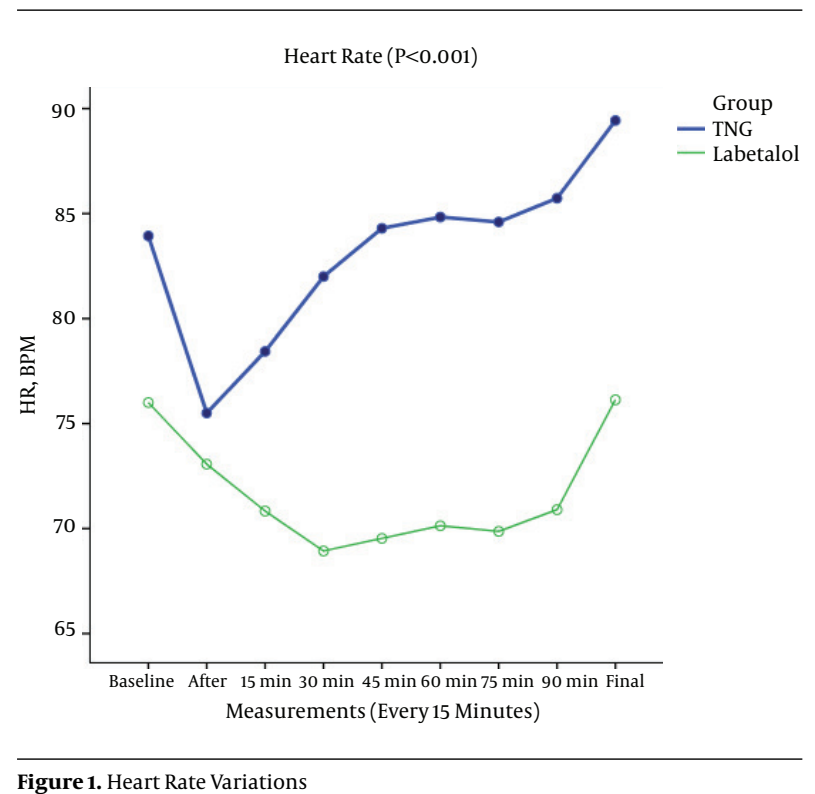

There was a significant difference between the 2 groups in terms of systolic $(\mathrm{P}<0.001)$, diastolic $(\mathrm{P}<0.002)$, and the mean arterial blood pressure variations $(\mathrm{P}<0.001)$ as shown in Figures 2-4. According to the results in the TNG group, there was a significant higher heart rate, but also significant lower systolic, diastolic, and mean arterial blood pressure in comparison to labetalol group at the same times.

Surgeon's satisfaction from the surgical field, in the TNG group was significantly more than that of labetalol

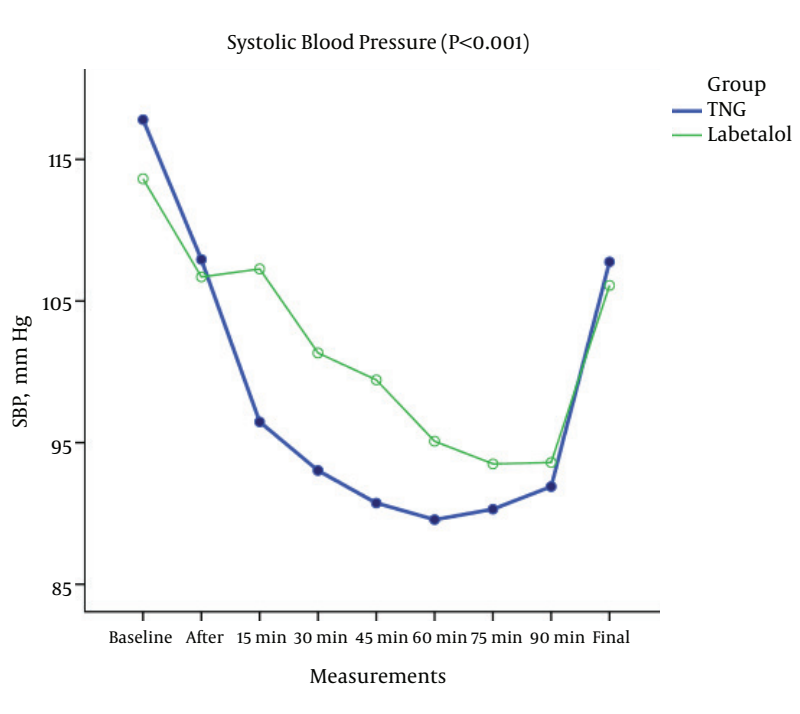

Figure 2. Systolic Blood Pressure Variations

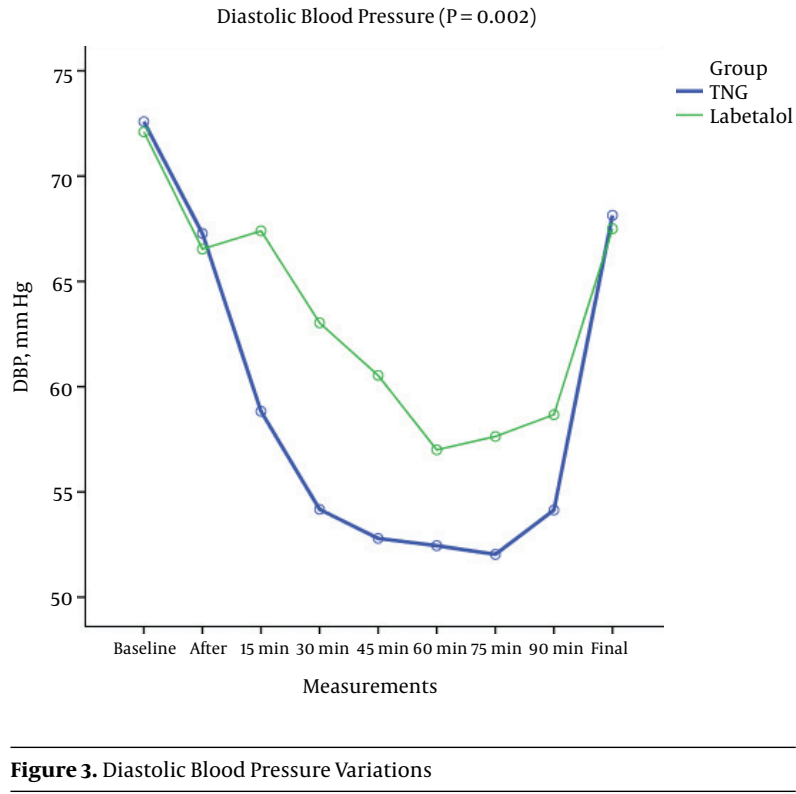

group $(\mathrm{P}<0.001)$ shown in Figure 5 , based on the rating score.

\section{Discussion}

The results of the current study demonstrated that the administration of labetalol as the sole drug to induce controlled hypotension was not effective enough. In order to reach the target blood pressure ( $\mathrm{MAP}=60$ to $65 \mathrm{mmHg}$ ) in nearly most cases (90\%) it was indispensable to use other 
Table 1. Demographic and Baseline Hemodynamic Parameters in the Study Groups

\begin{tabular}{|c|c|c|c|}
\hline Variable & TNG & Labetalol & P Value \\
\hline Age & $30.9 \pm 5.1$ & $31.2 \pm 5.1$ & 0.823 \\
\hline Male /female (percent) & $43.3 / 56.7$ & $50 / 50$ & 0.605 \\
\hline Body mass index & $25.1 \pm 2.6$ & $24.5 \pm 2.3$ & 0.416 \\
\hline Heart rate & $83.9 \pm 18.8$ & $76 \pm 15.7$ & 0.082 \\
\hline Systolic BP (mmHg) & $117.8 \pm 8.7$ & $113.6 \pm 8.73$ & 0.07 \\
\hline Diastolic BP (mmHg) & $73 \pm 8.3$ & $72.1 \pm 7.8$ & 0.653 \\
\hline Mean arterial $\mathrm{BP}(\mathrm{mmHg})$ & $84.4 \pm 5.7$ & $84.5 \pm 7.4$ & 0.923 \\
\hline Oxygen saturation (\%) & $97.9 \pm 0.6$ & $97.8 \pm 0.5$ & 0.672 \\
\hline
\end{tabular}

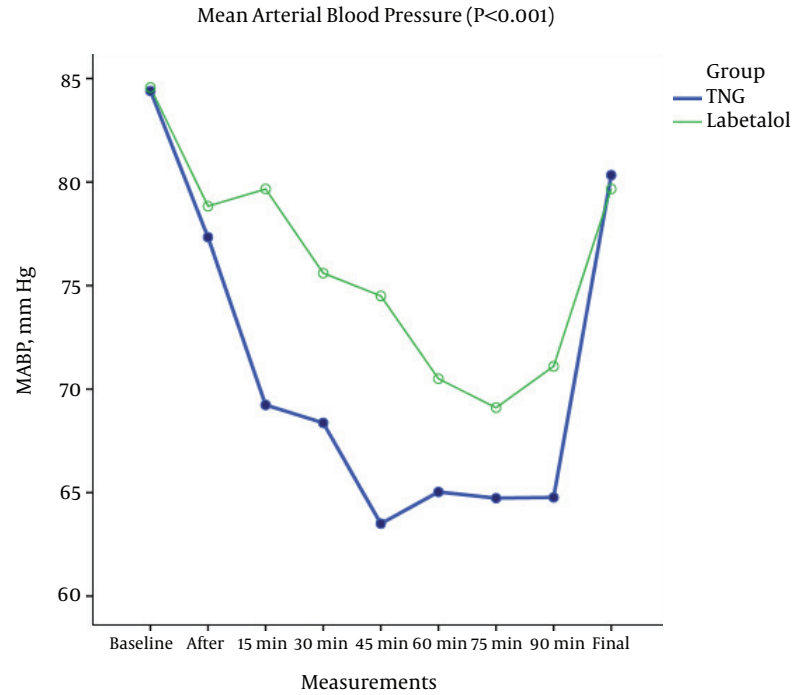

Figure 4. Mean Arterial Blood Pressure Variations

agents such as isoflurane. This result was not in accordance with those of other studies, which all, rather numerous, had unanimously stated that labetalol was a convenient and in some cases even an ideal drug to induce controlled hypotension. An example of such was Nagat S. et al. (13) that, similar to the current study, utilized labetalol and TNG to induce controlled hypotension in sinus endoscopy operations and deduced that both drugs were effective and safe, but labetalol was introduced superior as it improved the visualization of surgical field with a lower (and safer) levels of hypotension; and also a lower level of hemorrhage with labetalol in the current study was due to less tachycardia in comparison to TNG. In another study by Sajedi et al., (14) regarding a comparison of labetalol and remifentanil administration to in-

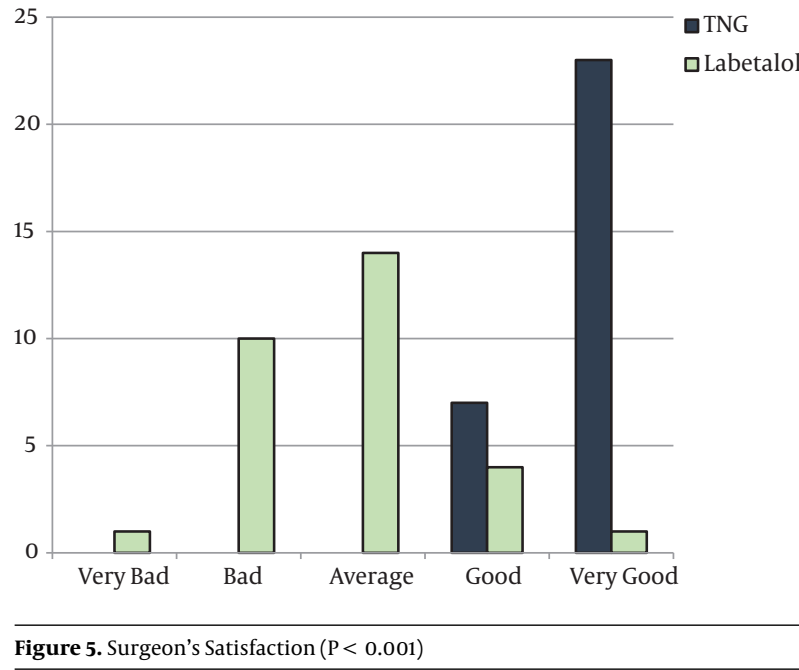

duce controlled hypotension while performing a sinus endoscopy, the authors concluded that despite the similarity of hemodynamic variables in both studied groups, a higher measure of hemorrhage and other complications were recorded in the labetalol group. Also, surgeons were more satisfied with the operation field conditions, while using remifentanil compared to labetalol; a result nearly similar to that of the current study.

In the current study, bleeding volume was not significantly different between the 2 groups. On the other hand, surgeon's satisfaction score from surgical field was higher in TNG group than the labetalol and this difference was statistically significant. This paradoxical fact could be probably explained by long onset time of labetalol in comparison with TNG in producing their hypotensive effects. It means that in the first minuets of the operation, which labetalol still had not played its hypotensive effect; there was more bleeding tendency in this group that challenged the 
surgeon for more hemostatic control by suctioning and packing the field frequently. Although this event made the surgeon less satisfied with labetalol group in comparison to TNG, it could not affect the volume of bleeding significantly and make any statistical important difference in this group compared with TNG group. In agreement with the current study findings, Eltringham et al., found no significant difference in decreasing the volume of bleeding between the 2 drugs in middle ear microsurgery (7). They concluded that both drugs were the useful choices to induce hypotension and decrease blood loss in such surgery.

Yasameen et al., evaluated the effects of labetalol and nitroglycerine on 2 groups of patients undergoing spinal surgery. One group received TNG, 1000 microgram, and the other group received labetalol, $5 \mathrm{mg}$, intravenously. They found a significantly higher score for surgical field quality and less bleeding in labetalol group (15). It is also interesting that they achieved these results with a much lower dose of labetalol as $5 \mathrm{mg}$.

In a study conducted at Shiraz University of Medical Sciences, Shiraz, Iran, the effects of labetalol and TNG on bleeding and surgical field quality in septorhinoplasty were evaluated. In the mentioned study, 60 patients (ASA1, 2 ) were randomized into 2 groups. The mean volume of bleeding was $117.8 \mathrm{~mL}$. There was no significant difference in terms of bleeding or surgical field quality, but they found that surgeon was a little more satisfied with surgical field in TNG than that of labetalol (although not statistically significant). Therefore, they suggested that more studies with larger sample sizes are necessary to establish the results (16).

In the current study, the mean blood pressure was higher and surgeon's satisfaction with surgical field was less that of the labetalol group and unexpectedly, there was a need for isoflurane in most of the patients (90\%) in the labetalol group to achieve the target blood pressure. It means that hypotensive effects of labetalol were so poor to such an extent that made the authors to use isoflurane frequently. Adding isoflurane to other anesthetic agents could have resulted in longer recovery time or more complications such as emergence of agitation and postoperative nausea and vomiting that were not concluded in the primarily designed variables to be documented in the current study, but they are well known complication of volatile anesthetics.

One of the limitations of the current study was the recommendation about maximum safe dosage of labetalol, which was $300 \mathrm{mg}$ in 24 hours (this limit was reached in 60 to 90 minutes to $4 \mathrm{mg} /$ minute infusion rate). Another confronted limitation was the complication of bradycardia that necessitated atropine infusion that in turn induced tachycardia and hypertension.
The small amount of hemorrhage in rhinoplastic surgery, which was mainly of capillary origin, made the estimation of bleeding volume inaccurate by the methods used in the current study. Therefore, it was suggested to precisely weigh surgical gauzes before and after packing to obtain net blood loss.

\subsection{Conclusion}

According to the results of the current study, it can be concluded that TNG, compared to labetalol, and prescribed with the tested dosage, was a more convenient drug to induce controlled hypotension in septorhinoplastic surgery as it caused hypotension more rapidly and provided a better surgical field for the surgeons.

\section{Acknowledgments}

Authors are thankful to all people who helped with the current study in Firoozgar hospital, especially anesthesia technicians and surgical team and pharmacy staff.

\section{Footnote}

Authors' Contribution: Study concept and design: Ali Khatibi; data collection: Fatemeh Parsa; analysis and interpretation of data: Mohamadreza Ghodraty, Ali Khatibi; drafting of the manuscript: Ali Khatibi; study supervision: Faranak Rokhtabnak; revision of manuscript: Mohamadreza Ghodraty, Mojtaba Maleki

\section{References}

1. Ragab SM, Hassanin MZ. Optimizing the surgical field in pediatric functional endoscopic sinus surgery: a new evidence-based approach. Otolaryngol Head Neck Surg. 2010;142(1):48-54. doi: 10.1016/j.otohns.2009.10.021. [PubMed: 20096223].

2. Cincikas D, Ivaskevicius J, Martinkėnas JL, Balseris S. A role of anesthesiologist in reducing surgical bleeding in endoscopic sinus surgery. Med(Kaunas). 2010;46(11):730-4.

3. May M, Levine HL, Mester SJ, Schaitkin B. Complications of endoscopic sinus surgery: analysis of 2108 patients-incidence and prevention. Laryngoscope. 1994;104(9):1080-3. doi: 10.1288/00005537-19940900000006. [PubMed: 8072353].

4. Simpson P. Perioperative blood loss and its reduction: the role of the anaesthetist. BrJ Anaesth. 1992;69(5):498-507. [PubMed:1467083].

5. Degoute CS. Controlled hypotension: a guide to drug choice. Drugs. 2007;67(7):1053-76. [PubMed: 17488147].

6. Goldberg ME, McNulty SE, Azad SS, Cantillo J, Torjman M, Marr AT, et al. A comparison of labetalol and nitroprusside for inducing hypotension during major surgery. Anesth Analg. 1990;70(5):537-42. [PubMed: 2082945].

7. Eltringham RJ, Young PN, Littlejohns PA, Robinson JM. A comparison of glyceryl trinitrate and labetalol as hypotensive agents in microsurgery of the middle ear. Eur Heart J. 1988;9 Suppl A:201-3. [PubMed: 3137067]. 
8. Fahed S, Grum DF, Papadimos TJ. Labetalol infusion for refractory hypertension causing severe hypotension and bradycardia: an issue of patient safety. Patient Saf Surg. 2008;2:13. doi: 10.1186/1754-9493-2-13. [PubMed: 18505576].

9. Wilson DJ, Wallin JD, Vlachakis ND, Freis ED, Vidt DG, Michelson EL, et al. Intravenous labetalol in the treatment of severe hypertension and hypertensive emergencies. Am J Med. 1983;75(4A):95-102. [PubMed: 6139020].

10. Vaughan LM, Sudduth CD, Sahn SA. Long-term continuous infusion of labetalol. Chest. 1991;99(2):522. doi: 10.1378/chest.99.2.522b.

11. Jivraj S, Mazer CD, Baker AJ, Choi M, Hare GM. Case report: profound hypotension associated with labetalol therapy in a patient with cerebral aneurysms and subarachnoid hemorrhage. Can J Anaesth. 2006;53(7):678-83. doi:10.1007/BF03021626. [PubMed:16803915].

12. Varon J, Marik PE. Perioperative hypertension management. Vasc Health Risk Manag. 2008;4(3):615-27. [PubMed: 18827911].
13. Nagat S, EL-Shmaa NS, Alsaid AEH, Younes A. To assess the efficacy of labetalol versus nitroglycerin for induction of controlled hypotension. JCA. 2017;39:154-8.

14. Sajedi P, Rahimian A, Khalili G. Comparative evaluation between two methods of induced hypotension with infusion of Remifentanil and Labetalol during sinus endoscopy. J Res Pharm Pract. 2016;5(4):264-71. doi: 10.4103/2279-042X.192463. [PubMed: 27843963].

15. Yeasmeen S, Siddique MRU, Islam A, Aktaruzzaman AKM, Banik D, Hye A. Use of labetalol and glyceryl trinitrate for induced hypotension in spine surgery- A comparative study. J Bangladesh Soci Anaesthesiolog. 2014;22(2) doi: 10.3329/jbsa.v22i2.18141.

16. Hadavi MR, Zarei Y, Tarogh S. Comparison of effects of labetalol and nitroglycerine on intraoperative blood loss and surgical field quality in rhinoplasty surgery. World J Plast Surg. 2015;4(1):60-5. [PubMed: 25606478]. 